\title{
The Use of Orientalist Stereotypes and the Production of Kitsch: Tourism Architecture in Turkey in the Face of Social Change ${ }^{1}$
}

\author{
Zeynep Çiğdem UYSAL ÜREY \\ Yrd. Doç. Dr., Çankaya University, Department of Architecture \\ Cukurambar Mah. Öğretmenler Cad. No: 14, 06530 Ankara, TURKEY
}

Tel: 031228445 00, Faks: 03122864078 - e-mail: zeynepuysal@ cankaya.edu.tr

\begin{abstract}
This study aims to examine the imposition of an orientalist perspective to architectural productions and intends to show how that perspective creates examples of kitsch by means of its use of orientalist stereotypes. It is acknowledged today that there is a strong inclination in touristic contexts to form and enliven imaginary worlds that conjure superficial ideas about the settings in tourists' minds, by effectively using architecture. This is specifically true when the touristic settings are located in the so called 'Orient' or in contexts that have lineage with orientalist dreams. Such practices by the use of stereotypical orientalist images in architecture give rise to the creation of 'kitsch'.

In this study, these concepts are studied theoretically and exemplified by way of architectural cases from Turkey. The cases are comprised of five specific touristic establishments in Antalya, which are namely the Topkap1 Palace World of Wonders, Kempinski Hotel the Dome, Mardan Palace, Crowne Plaza Hotel, and Delphin Palace Hotel. These architectural productions are analyzed formally by in-site survey and discussed as architectural consequences of the orientalist standpoint.

It has been found out that the selected touristic establishments consciously use the stylistic stereotypes of the Orient to recall stereotypical Oriental images. In that way they also carry within themselves all of the features that make art works instances of 'kitsch'. This study suggests that such trials by the use of stereotypical orientalist images in architecture create examples of kitsch. The specific architectural cases are interpreted in this framework as the architectural consequences of the internalization of the orientalist standpoint, and on account of that, as forms of 'Orientalist Kitsch'.
\end{abstract}

Keywords: Orientalism, Stereotypes, Kitsch, Architecture, Tourism, Turkey

\footnotetext{
${ }^{1}$ This paper has been presented at the $2^{\text {nd }}$ International Conference on Science, Culture and Sports, 30 October1 November 2013, Antalya and is based on the author's research paper prepared for the AH 548 course (Aesthetics and the Psyche) that was taken at the Middle East Technical University in 2003.
} 


\section{Introduction}

When the orientalist point of view is internalized, the subjects of the so-called 'orient' reflect themselves with the characteristics that the orientalists choose to see them. This becomes especially noticeable when the architecture of tourism is considered. Since the aim of these touristic establishments is to attract the tourist that comes to the context with a possible orientalist view, they set the architecture as a stage that uses those stereotypical images to lure their customers. On that account, the aesthetics of those architectural productions fall to a category that could be explained by the notion of 'kitsch'.

In the following paragraphs, these notions are discussed in detail and the selected cases from the touristic architectural scene of Turkey are studied with such a perspective. Accordingly, the study is structured around four discussions, which are: the orientalist look and the use of stereotypes; orientalist architecture and stereotypic forms; notions of stereotype and kitsch; and the examination of the cases from Turkey.

\section{Possessing the Orientalist Look and the Use of Stereotypes}

Orientalism, as Edward Said defines it, is a corporate institution and a systematic discourse for dealing with the Orient. It develops as a Western style of thought and appears as a constructed discourse for dominating, restructuring and obtaining authority over the Orient. Initiated by the British and French, as a colonial, cultural enterprise in the 18th century, Orientalism develops as a systematic European discipline producing the Orient politically, sociologically, ideologically and imaginatively. (Said, 1995: 4) The discourse, accumulating knowledge and documents over the Orient systematically, works as an interdependent and almost autonomous discipline. As a consequence of this constructed process of development and way of perception, the 'Orient' appears not as a free subject of thought and action, but as a subject of Western conceptions and representations about the 'Orient'. (Kennedy, 2000: 1449)

This self-containing and self-reinforcing closed discipline based on European Atlantic power over Orient, appears as a 'myth system` also constructing its hegemony over culture. (Kennedy, 2000: 14-49) In this context, emerging both as a conscious discourse and a collection of European fantasies over Orient, Orientalism, as stated by Said, exerts a threeway pressure: on the Orient, on the Orientalist and on the Western consumer of Orientalism. This way, Orient is 'Orientalized' for the Orient, the Orientalist and for the Western consumer of this discourse. (Said, 1995: 4)

In this framework, Orientalism as a discourse acts as a 'filter' on the perception of the Orient; and possessing the look of Orientalism therefore, is to possess the look through this 'filter'. (Said, 1995: 1-18) This filtered look of Orientalist discourse brings forth a fixed set of ideas about the characteristics of the Orient and the Orientals, which are called the 'cultural stereotypes'. As Sibel Bozdoğan states, these 'cultural stereotypes' bring forth standardization over the perception and reception of the Orient. They reduce the actual complexity and diversity of the Orient into an 'enframed', objectified, and representable entity, furthermore, they establish it as a standing reserve for Western domination. (Bozdogan, 1988)

The image of the orient, which is enframed through the stereotypic representations "can now be reproduced, multiplied and transported elsewhere and reconstructed ultimately to 
become an object of consumption." (Bozdogan, 1988) This form of appropriating the Orient by the process of stereotyping, "prepares the Orient as a stylistic repertoire, a catalog of images ready at hand to be consumed at will." (Bozdogan, 1988: 38-45) As a consequence, it also appears as a stylistic category in architecture.

\section{Orientalist Architecture and the Implementation of Stereotypic Forms and Motives}

As stated by Bozdoğan, by the accumulation of the materials and cultural goods brought back to Europe by the travellers and colonialists, the oriental architecture became an object of display and emerged as a stylistic possibility in front of the Western community. From that time onwards, by the private consumption of Orient in pleasure gardens and villas to the public consumption by the international fairs, the Orient appeared as a "make believe Oriental pastiche". (Bozdogan, 1988: 38-45) The Orientalist forms and materials, obtained from the Orientalist documents and pictorial representations were utilized to evoke personal or communal fantasies over the Orient.

Those stylistic forms and motives turned out to be a set of fixed elements, namely the formal stylistic stereotypes, reproducing themselves in Orientalist architecture. They were used as an exploration of 'exotic' possibilities and were mainly utilized for the leisure pursuits of the masses. (MacKenzie, 1995) As Mackenzie puts it, those formal stylistic stereotypes consisted of elements such as the kiosks, domes, pointed and cusped arches, fountains and minarets, spandrel and cornice decorations, ceramics, textiles, ironworks, tile works and stained glasses. It was through these fixed stylistic stereotypes that the stylistic display of Orient was achieved and confirmed.

However, what seems as more striking in this context is that the appropriation of this stylistic attitude did not stay limited to the use and consumption of Westerners; on the contrary, the Orientals themselves also adapted it to themselves. Therefore, as asserted by Bozdoğan, the stylistic display of the Orient appears by no means as an entirely Western attitude, on the contrary the Orientals themselves have employed the orientalist images as “instant identity kits". (Bozdogan, 1988: 38-45)
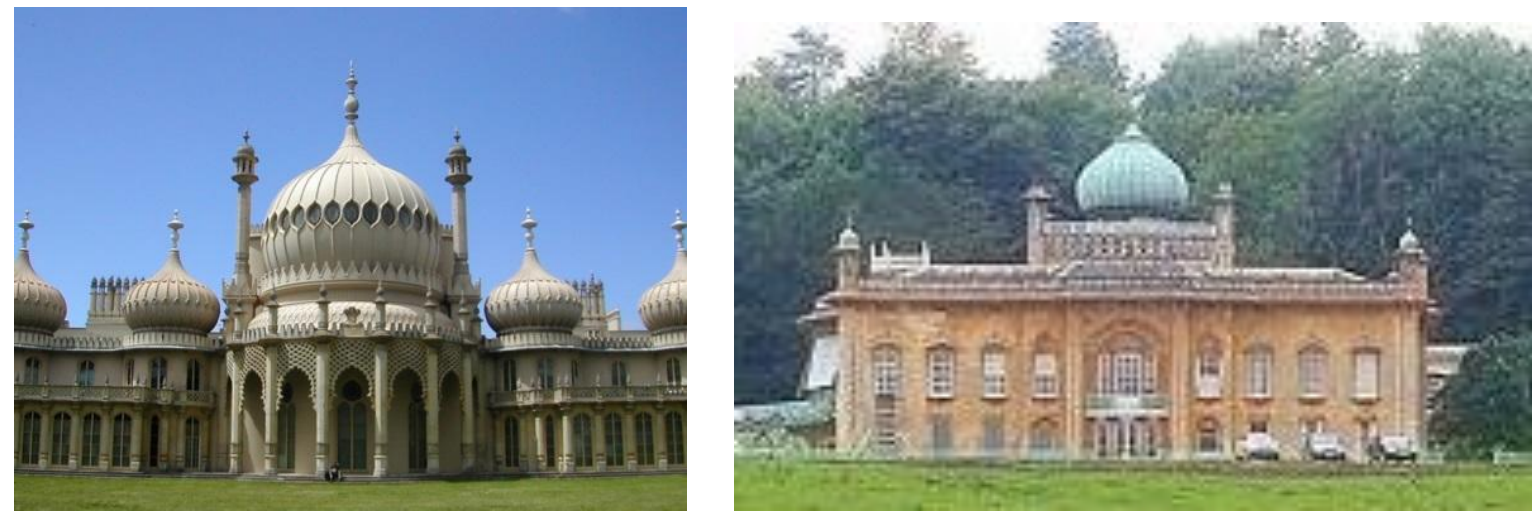

Figure 1, 2. Examples of Orientalist Architecture in Europe: Brighton Pavillion, Brighton, England (left), Source: http://en.wikipedia.org/wiki/File:Brighton_Royal_Pavilion.jpg;

Sezincote House, Gloucestershire, England (right), Source:

http://en.wikipedia.org/wiki/File:Sezincote_House.jpg 


\section{The Stereotype and Kitsch}

Stereotype, namely the fixed set of ideas held about the characteristics of a particular person or a thing, is conceptually in close connection with the notion of kitsch. As Renato Poggioli suggests, both the stereotype and the kitsch are the products of a continual process of standardization. They are both made common place and were put into general or universal use. As stated by Poggioli, where the stereotype signifies the vulgarity and fixed banality of a theme, kitsch underlines the mediocrity and banality of a particular work of art. Thus, where the stereotype is associated more with ideas and themes, the kitsch appears as connected with the evaluation of art works. (Poggioli, 1968: 79-85)

They have both been established to perpetuate the standardized and clichéd themes and forms. Hence, the forms abandoning their newness and novelty that continue to repeat themselves, are turned either into kitsch or stereotype. In this context, all synonyms that could serve to define both kitsch and stereotype appear as connoting not a new beauty, but a beauty grown old or familiar. (Poggioli, 1968: 79-85) Therefore, the notion of 'familiarity' is common in both cases.

Kitsch is broadly treated in two approaches; first as a historico-social concept born and cultivated in the Modern era, and second as an aesthetic, perhaps as an anti-aesthetic concept. (Kilickiran, 1996) In the context of this study, kitsch is treated as an aesthetic concept and defined in connection with the notion of stereotype. Various characteristics of the notion of kitsch could be listed as follows:

As mentioned previously, the first notion that defines kitsch is familiarity. As Gadamer remarks, kitsch is enjoyed not for the sake of some artistic or creative quality but because its familiarity that provides us with what we already know. (Gadamer, 1986) On this basis, all forms of kitsch depend on our biased familiarity with the items shaped before us, in order to catch and direct our attention, without spending any effort.

A second quality that defines kitsch is that it resembles art by imitating it, but lacks its true creative quality. As various scholars agree, kitsch uses 'artistic means to satisfy a certain temporary need', but it is not a product of creative artistic effort. (Eco, 1989) It is related with repetition, banality and tiredness. (Broch, 1969) For this reason, in the theory and criticism of art, 'kitsch' is defined as the anti-art and represents the 'bad taste', and the 'tasteless', 'banal' or 'arabesque' works. (Kilickiran, 1996: 1-20)

A third characteristic of kitsch is that it delivers itself to a well-defined audience of ordinary consumers, to 'communicate varieties of highly predictable messages in 'stereotyped' aesthetic packages'. (Calinescu, 1986) For this audience, it aims to create immediate effects with a claim of being art.

A fourth characteristic of kitsch is its being "the systematic attempt to escape from daily reality". (Eco, 1989) Using its impressive image, kitsch creates a lure to satisfy its viewers.

A fifth characteristic of kitsch is its being out of its existing context, or in other words its 'out of contextuality'. As Gillo Dorfles stresses, this instance of kitsch occurs, when a single element or a whole work of art is transferred from its real status and used for a different purpose from the one for which it was created for. This happens when the great historical monuments are used for purposes other than their original ones. What make these monuments to turn to objects evaluated as kitsch, results from their improper reproduction and the substitution of different sentimental values over their real values. (Dorfles, 1969) This is 
actually an instance that shall be discussed when the architectural cases in Turkey are examined.

\section{Touristic Architecture: Demonstrating the Stylistic Stereotypes of the Orient and Using the Benefits of 'Kitsch'}

As stated by Ali Behdad, producing an Orientalist attraction for the foreign tourist is a beneficial action to prepare the grounds to satisfy their desire for the Orient. (Behdad, 1994) This desire of the tourists can be likened to the desire to see the 'Other' and on this basis, the mediums that are created by such touristic establishments that use stylistic orientalist stereotypes, work as the means for the tourists to satisfy their desire to see and experience the 'Other'. As Asena Günal argues, whether the tourists are aware or unaware, these kinds of touristic attractions are kinds of 'staged authenticities' or places built as the 'living museums'. (Gunal, 1998) They satisfy the tourists' desire for the expected 'ethnical, culturally traditional, namely stereotypic authenticity'.

Either the desire of the tourists is in this track or not, it is obvious that both the tourists and the producers of this setting cooperate in this understanding. In Dean MacCannell's words 'in this make believe world, the possible tourists playfully cooperate in the game'. (MacCannell, 1976: 43-50) For these tourists everything in those settings are signs of a 'typical' cultural practice. (Culler, 1988: 155) Although this is making up of generalizations about the character of the tourist, we may observe in our daily life that this statement has a relevant point. Touristic establishments that use the stylistic stereotypes of the Orient, recall the Oriental images in the minds of the possible tourists and in that sense they demonstrate the 'internalization' of this view.

However, by this type of presentation, an unhealthy situation occurs: an identity and scenery which does not actually exist becomes affixed and perpetuated. As argued by Didem Kilıçkiran, in most of the tourism complexes in Turkey, where profit making is the primary goal, the main architectural attitude appears to be producing the 'exotic' and 'Orientalist' image, which is accepted as the image of Turkey in the West. (Kilickiran, 1996) Such touristic establishments produce this Orientalist image as an endorsement and perpetuation of the existing Orientalist standpoint. This way, in Said's words, 'the Orient participates in its own Orientalizing'. (Said, 1995: 325)

Displaying these kinds of fake identities by using the stereotypical oriental images, such touristic establishments also carry within themselves all of the features that make art works instances of 'kitsch': they use the stereotypical oriental images out of their context and time and give them different functions; they sell themselves with the help of a stereotypical repetition but not true artistic creation; they address themselves to a 'well-defined audience' of ordinary touristic consumers; they use the 'familiarity' of oriental images to deliver the message to the tourists that they can satisfy their Oriental dreams; and they are also the attempt(s) to escape from daily reality" (Eco, 1989), as they already belong to the entertainment industry. With these characteristics, those touristic establishments in Oriental contexts, which were built with stereotypical oriental images, could be interpreted as forms of 'Oriental Kitsch'. 


\section{Forms of Orientalist Kitsch: Some Examples From the Touristic Architecture in Turkey}

In the light of the discussions held above, five specific architectural productions in the province of the city of Antalya shall be discussed subsequently. These are namely Topkap1 Palace World of Wonders, Kempinski Hotel The Dome, The Mardan Palace, Crowne Plaza Hotel, and Delphin Palace Hotel. These architectural productions will be interpreted as forms of 'Orientalist Kitsch'.

The first and maybe the most self-explanatory example is the Topkap1 Palace World of Wonders. Being a hotel situated in Antalya, the hotel is produced as an exact reproduction of the original Topkap1 Palace situated in Istanbul, by the International WOW Hotels group. Being built as an exact reproduction of the original Topkap1 Palace in İstanbul and being situated in the most touristically popular and active region of Turkey, the hotel aims to attract the attention of mainly foreign tourists. Its being the reproduction of an Ottoman palace is no way a coincidence in this sense. This results from the aspiration to stimulate the tourists' expectations of a possible Oriental experience out of Turkey.

By the inclusion of various stereotyped oriental elements like the domes, pointed arches, kiosks, fountains, ceramics, textiles, iron or tile works, it maintains a display of a stereotyped orientalist scenery. In addition, by providing some of the 'orientalist' facilities like the 'hamam' and the 'bazaar', or by organizing various eating facilities in the settings like Ottoman kiosks, with meals served by waiters dressed in Ottoman costumes, the hotel also contributes to the stereotypical Oriental life style. By creating this 'staged authenticity', the hotel recalls the Oriental images in the minds of tourists and provides the stylistic display of the Orient.

The use of these stereotypical orientalist images at the hotel also makes it suitable to be interpreted as a form of 'kitsch'. Being built as an exact reproduction of a genuine palace, the hotel transfers the palace from its real status and uses it for a different purpose, out of its context. As a result of this execution, the hotel reduces the value of the original palace improperly and substitutes different sentimental values over its real value. Moreover, solely being a 'reproduction', without any concern for an innovation, it emerges as an example of how a production devoid of the artistic creation sells itself with the help of a stereotypic repetition. With this repetition, it addresses itself to a 'well-defined audience' of ordinary touristic consumers with a message that they can satisfy their oriental desires. For this, it uses the 'familiarity' of Orientalist elements that the tourist is expecting out of an Orientalist architecture. As such, it also becomes a real 'escape from daily reality', which coincides with the title of the managerial firm, namely 'World of Wonders'. Therefore, all in all, the hotel holds the orientalist standpoint in its creation and when all of its characteristics are considered, it would not be wrong to interpret it as a form of 'orientalist kitsch'. 

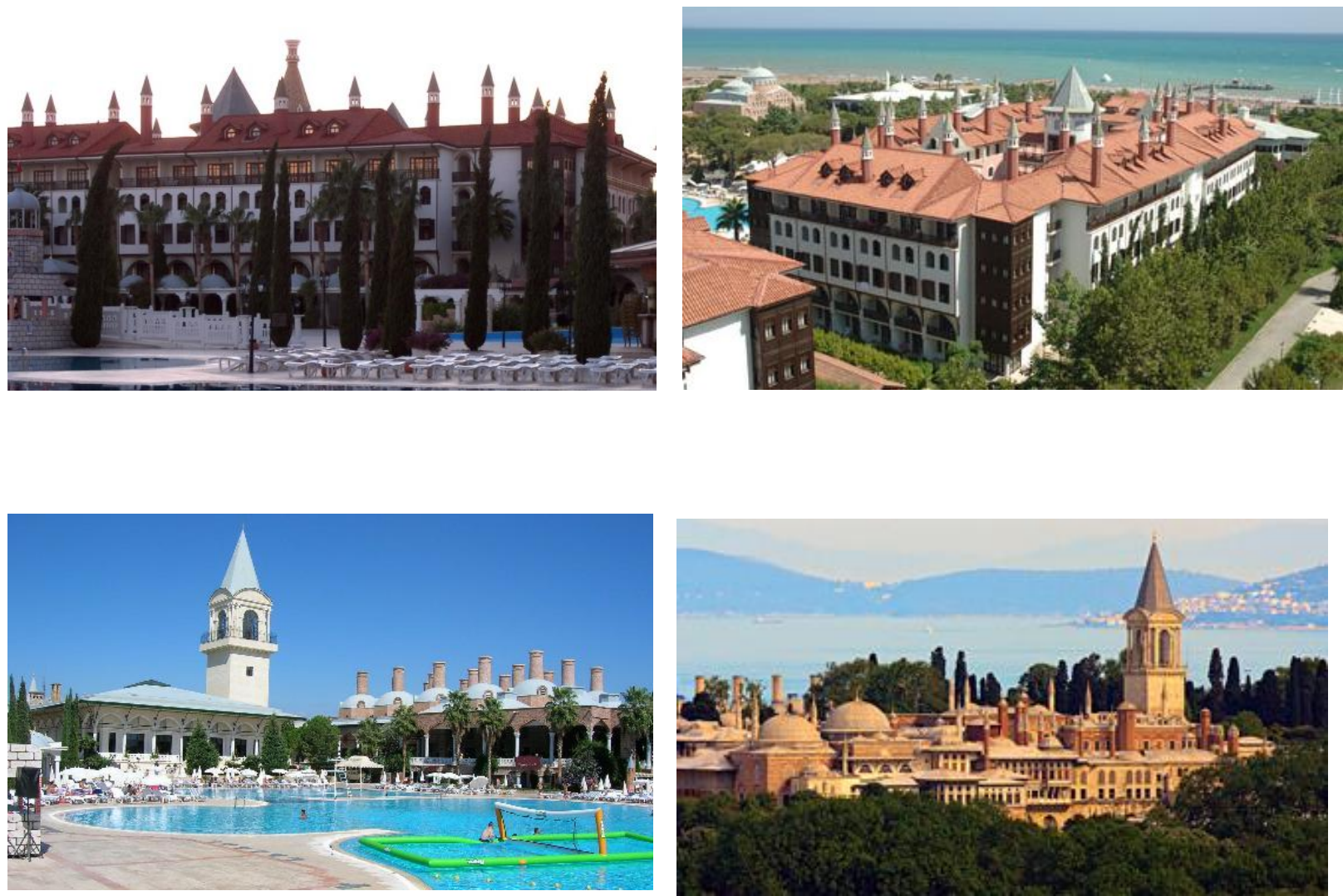

Figure 3, 4, 5, 6. Original Topkapi Palace in Istanbul (upper left), Source: www.turkeytourguide.comwp-contentuploads201204Topkap\%C4\%B1-Palace-Museum.jpg; Topkapi Palace World of Wonders Hotel in Antalya (upper right, lower left and right), Source: http://www.wowhotels.com/wowtopkapipalace.asp

The rest of the cases share important characteristics with each other and are different from Topkap1 Palace World of Wonders in the sense that they are not exact replicas of historical buildings, but they are influenced by Ottoman or Seljuk architecture.

Kempinski Hotel the Dome is said to be influenced from Seljuk architecture. Belonging to the international Kempinski group, the hotel resembles Seljuk caravanserais or mosques with its pointed arches, domes, carved ornaments, mass formation, revaks, double arches, interior decorations and ornamentations, and the carved symbol of the double headed eagle. The main gate of the hotel is very obviously made to resemble the grand gates of Seljuk mosques and caravanserais. The use of stylistic oriental stereotypes and the aim of satisfying the oriental expectations of the tourists are apparent, however, it must be stated that the design of the hotel seems to be the outcome of an architectural interpretation but not of pure imitation. For this reason, although it is stylistically out of context, has a well-defined audience and uses the familiarity of oriental images to provide the escape from reality, it would be hard to interpret it as a form of kitsch. It could be interpreted as an orientalist architectural production, but not exactly as a kitsch. 

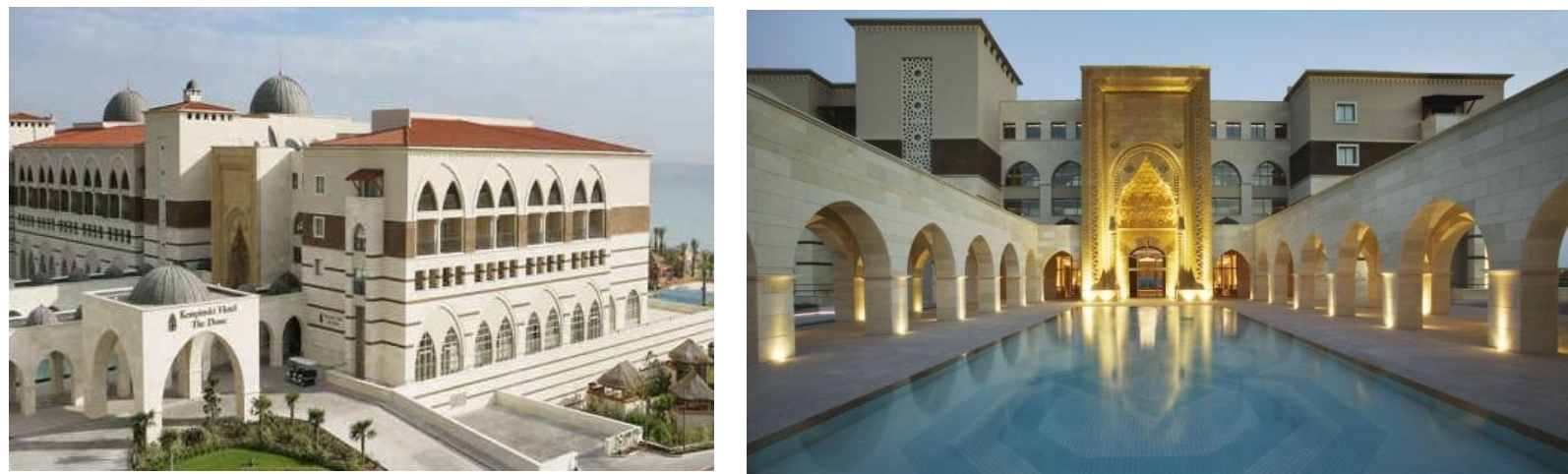

Figure 7, 8. Kempinski Hotel the Dome in Antalya (left and right), Source: http://www.kempinski.com/tr/belek/hotel-the-dome

Mardan Palace is a very interesting case in terms of its production, use of materials and historical references. The owner of the hotel is the Azerbaijan billionaire Telman Ismailov. It is said that Ismailov was deeply fond of his holidays in Istanbul, but he longed for the beach, so he wanted to build the replicas some of the important architectural features of the city, such as Dolmabahce Palace and Maiden Tower. A total of 1.65 billion dollars were spent on this 560 roomed hotel. In its construction, 2500 tons of gold, 500.000 crystals and 23000 tons of Italian marble were used. Even the sand of the beach, 8000 tons in total, had been brought from Egypt. All in all, the hotel was built as a luxurious pleasure palace. (Edwards, 2009)

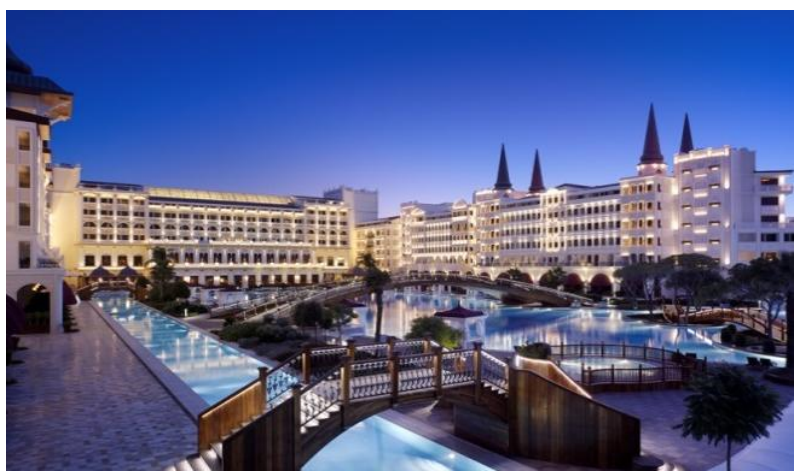

Figure 9, 10. Mardan Palace in http://www.mardanpalace.com/

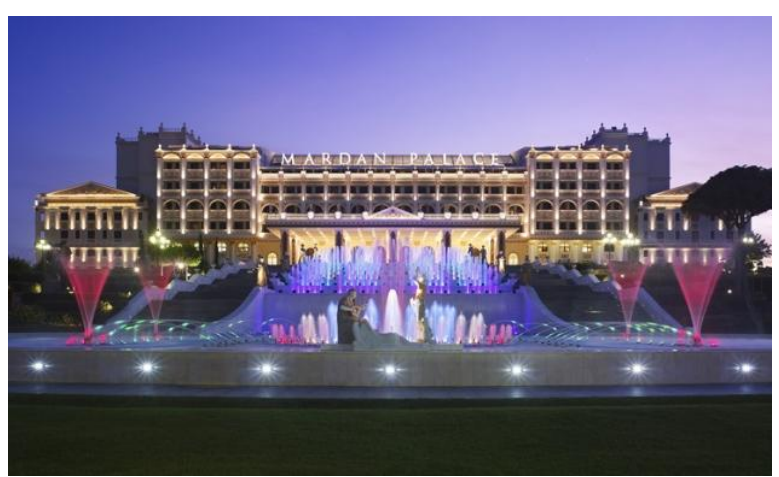

Antalya (left and right), Source:

The hotel building is mainly an ode to Dolmabahce Palace with its flowing staircases, interior decorations, Corinthian column capitals, domes, oriental ornamentations, chandeliers, carpets and stained glass art works. Next to the main hotel building, near the swimming pool, there is an exact replica of the Maiden Tower of Bosphorus. There is also a replica of the bridge that Leonardo da Vinci had designed for Halic but had never been built. Again, by reproducing the architecture of the past without any concern for context and by using the familiarity of oriental images to create a staged authenticity, the hotel could be interpreted as a form of 'orientalist kitsch'. 
The third case, Crowne Plaza has been inspired from Seljuk, Ottoman and Arabic architecture, but it is eclectic and used those sources mainly in a number of decorations. The most obvious use of an orientalist stylistic stereotype is found at the entrance façade, which was built in the form of a giant Seljuk gate. There are other orientalist details here and there, such as the ogee arches used at the interior, which are the results of an Arabic influence, the pointed arches at the facades, the domes, and the wooden kiosk at the central atrium. All in all they create an atmosphere that is full with orientalist connotations, but not that profuse as the others.

The last case, which is Delphin Palace, carries within itself again eclectic influences, which could be likened to Ottoman and Mughal architecture. The most obvious oriental elements of the hotel are the pointed golden domes, the biggest of which is sitting at the intersection of the two blocks of the hotel. They resemble the pointed domes of Taj Mahal or Badshahi mosque. The other stylistic stereotypes are mainly found at the interior decoration, such as the excessive use of golden ornamentations, the furniture, and the carpets. When compared with the two first cases, Delphin Palace creates an orientalist atmosphere, but not that dense as the others.
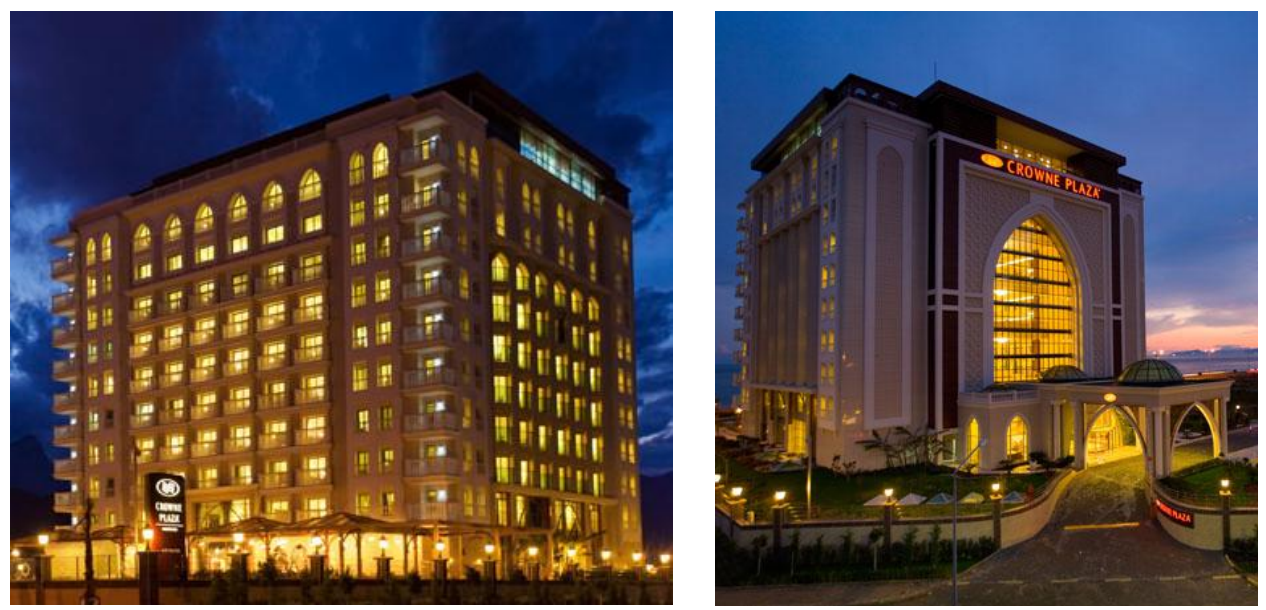

Figure 10, 11. Crowne Plaza in Antalya (left and right), Source: http://www.cpantalya.com/

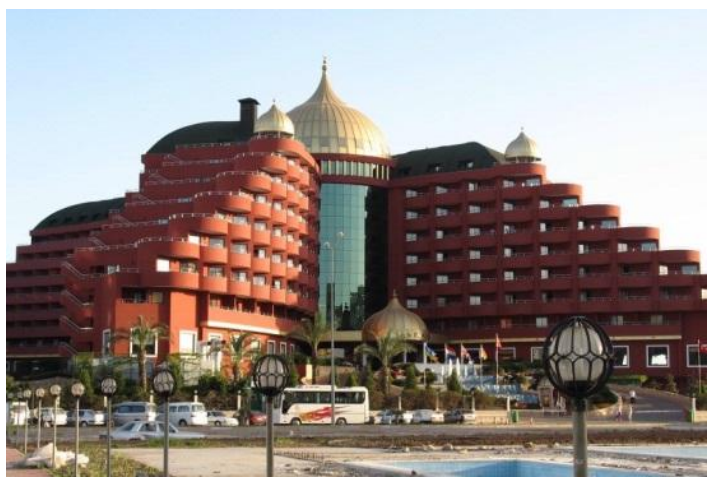

Figure 12, 13. Delphin Palace

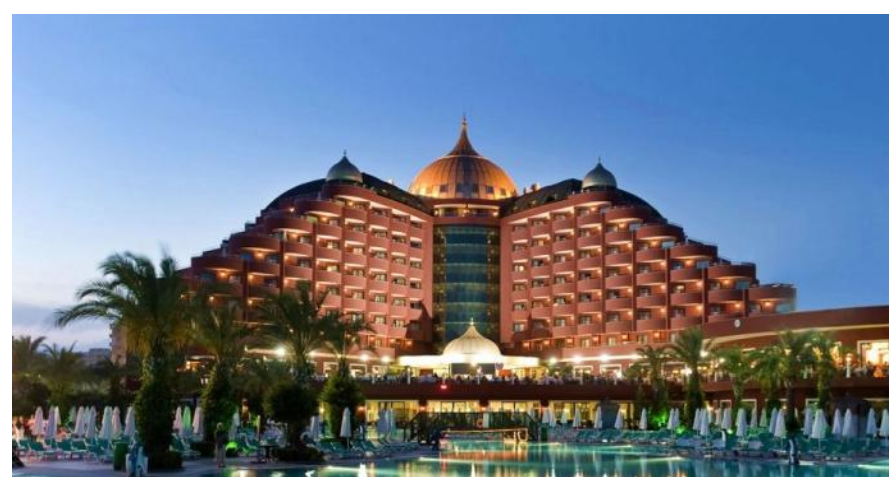

in Antalya (left and right), Source: http://www.delphinhotel.com/ 


\section{Conclusion}

Consequently, it could be said that the effort to meet the demands of the tourism industry by producing extravagant architectural productions eventually leads the way to such productions. We must admit that the concept of holiday bears the thought of escaping from reality and building hotels that look like stage sets that make us escape from our ordinary lives is understandable. However, it still does not cease our need of criticizing their motivations. The motivation of such touristic establishments, which is to use the stereotypical oriental images of the context to lure the tourists, form architectural products that lack an honest architectural approach. It is for this reason that such establishments could be interpreted as forms of 'Orientalist Kitsch'.

\section{REFERENCES}

Behdad A (1994). Belated Travellers: Orientalism in the Age of Collonial Dissolution. Durham: Duke University Press.

Bozdoğan S (1988). "Journey to the East:Ways of Looking at the Orient and the Question of Representation". Journal of Architectural Education. Volume 41, Number 4.

Broch H (1969). "Notes on the Problem of Kitsch". Kitsch: an Anthology of Bad Taste. Gillo Dorfles ed., London: Studio Vista Limited.

Calinescu M (1986). Five Faces of Modernity. Durham: Duke University Press.

Culler J (1988). 'The Semiotics of Tourism'. Framing the Sign: Criticism and its Institutions. Basil Blackwell, 155.

Dorfles G (1969). Kitsch: an Anthology of Bad Taste. London: Studio Vista Limited.

Eco U (1989). "The Structure of Bad Taste". The Open Work. Cambridge, Massachusetts: Harvard University Press.

Edwards G (2009). "The Mardan Palace Hotel, Turkey: Europe's brashest, wackiest, glitziest resort". [Online] Available: http://www.dailymail.co.uk/travel/article-1203838/The-MardanPalace-hotel-Turkey-Europes-brashest-

Gadamer HG (1986). "The Relevance of the Beautiful”. The Relevance of the Beautiful and Other Essays. Cambridge, UK: Cambridge University Press.

Günal A (1998). Orientalism from Travel Literature to the Discourse of Tourism. Unpublished Master's Thesis, METU, Ankara.

Kennedy V (2000). “Orientalism”. Edward Said: a Critical Introduction. Cambridge, UK: Polity Press, 14-49.

Kilıçkıran D (1996). Kitsch and Architecture: The Production of Kitsch in the Architecture of Turkey in 1980's and 1990's. Unpublished M.Arch Thesis, ODTU, Ankara.

MacCannell D (1976). The Tourist: A New Theory of the Leisure Class. New York: Schocken Books, 43-50.

MacKenzie JM (1995). "Orientalism in Architecture". Orientalism, History, Theory and the Arts. Manchester, UK: Manchester University Press. 
Poggioli R (1968). "Fashion, Taste and the Public". The Theory of the Avant-Garde. Cambridge, UK: Harvard University Press, 79-85.

Said EW (1995). Orientalism. London: Penguin Books. 